\title{
Nutritional evaluation of buckwheat genotypes and its utilization in the preparation of supplemented biscuits
}

\author{
Y. S. Dhaliwal and Ranjana Verma
}

\begin{abstract}
Six buckwheat samples were analyzed for physico-chemical characteristics. Crude protein, crude fat, ash, crude fibre, free fatty acids, free amino acids and trypsin inhibitor activity were assessed using standard methods. Attempts were made to utilize buckwheat grains flour in preparation of biscuits. Biscuits were supplemented with 10,20,30 and 40 per cent buckwheat flour. The prepared biscuits were evaluated for nutritional profile and sensory acceptability. Results of the study revealed that nutritionally rich and organoleptically acceptable biscuits can be prepared using buckwheat flour upto 40 per cent level of supplementation. Development of buckwheat fortified products will not only help cultivation and consumption of nutritionally and medicinally rich underutilized crop but will also help to combat the problem of malnutrition in vulnerable sections of society as buckwheat proteins have better amino acid composition with high levels of lysine.
\end{abstract}

Key Words : Buckwheat, Nutritional, Functional, Organoleptic, Biscuits

How to cite this article : Dhaliwal, Y.S. and Verma, Ranjana (2018). Nutritional evaluation of buckwheat genotypes and its utilization in the preparation of supplemented biscuits. Food Sci. Res. J., 9(2): 347-352, DOI : 10.15740/HAS/FSRJ/9.2/347352.Copyright@ 2018: Hind Agri-Horticultural Society. 